\title{
reconocimiento y elimimación de defectos de moldeo en la industria ladrillera
}

\author{
Ingeniero Jefe C. SCHLINKERT, Instituto para investigación de ladrillos, Essen
}

Die Ziegelindustrie, nos 7/8, abril 1968, pág. 167

\begin{abstract}
Los análisis del laboratorio móvil de ensayos han demostrado en el pasado año que en las fábricas todavía se producen defectos de moldeo y en número notablemente elevado. Estos defectos han llamado la atención, sobre todo, en la fabricación de ladrillos de formato grande.
\end{abstract}

En las fábricas con dispersiones en el moldeo, se manifestó, en diversas ocasiones, que las grietas, sobre todo en los nervios, no son decisivas en la prueba de la calidad, ya que, tanto los ladrillos con grietas como los que no las tenían, muestran casi la misma resistencia a la compresión.

Sin embargo, en ensayos de carga en la obra de fábrica se ve que no solamente es importante la resistencia a la compresión, sino también la resistencia a la tracción transversal en el ladrillo. Si hay grietas en los nervios de los ladrillos perforados altos, es natural que aquéllas tengan importacia en la resistencia de la obra de fábrica. Por lo tanto, a ser posible, hay que evitar las grietas en los nervios.

Si años atrás se opinaba que los defectos de moldeo quedaban atenuados al máximo si la barra salía plana de la boquilla, los recientes ensayos de compresión en las fábricas han demostrado que no basta sólo esta condición para producir ladrillos crudos de baja resistencia.

En este trabajo se exponen las experiencias de los ensayos de compresión realizados en el último año.

\section{Observaciones generales}

En muchos casos se maneja la idea de que la primera materia es sensible al secado, y esto se debe a que los ladrillos crudos secados rápidamente en secadores artificiales se agrietan en parte. Analizando los secadores se comprueba que en una misma hilera o en la misma cámara existen notables diferencias en el tiempo de secado, que a veces son de 3 a 4 días.

$\mathrm{Si}$, teniendo en cuenta la tendencia al agrietamiento, los ladrillos crudos se secan demasiado deprisa y hay que continuar disminuyendo aun más su tiempo de secado, se producen frecuentemente excesivas roturas. De esto se saca la consecuencia de que la primera materia de que se dispone es sensible al secado. 
Como ya se sabe, ladrillos crudos que acusan tensiones interiores, secados con la adecuada lentitud, pueden salir sin grietas de los secaderos. Según el punto de vista del autor sería más aconsejable no hablar de sensibilidad al secado, sino de sensibilidad al prensado.

Las pruebas realizadas con primeras materias han demostrado en numerosas ocasiones que no son por naturaleza sensibles al secado. Pero si, empleando secadores artificiales, se secan rápidamente piezas de arcilla moldeadas a mano y ladrillos crudos de barras prensadas de la misma masa, las primeras no presentan grietas, pero, en cambio, las presentan en muchos casos, los ladrillos crudos moldeados a máquina.

Antes de tratar de los defectos de moldeo propiamente dichos, es conveniente hablar del contenido de humedad de la masa a prensar. Como se sabe, influye, entre otras cosas, en el avance a la salida de la boquilla, incluso cuando a la prensa sinfín se la alimenta siempre con idénticas cantidades de material.

\section{Avance de la masa con diferentes grados d 3 humedad}

Siempre hay ocasión de experimentar las dificultades que se producen por la diferente humedad. Por eso, en prensas con accionamiento individual, se ha medido continuamente el consumo de corriente de los motores de accionamiento, resultando que de dicho consumo puede determinarse el contenido de agua de la masa. Es más, si se anota continuamente el consumo de fuerza de los diferentes grupos de la preparación, como son

- molino de rodillos;

- alimentador circular;

- mezcladora de doble eje;

- prensa,

mediante la conveniente adición de agua de amasado o vapor, es posible comparar el consumo de corriente de los distintos grupos y mantener así un contenido de agua en la masa casi constante.

En los rodillos hay que adicionar el mayor voiumen de agua. En las máquinas que siguen sólo hay que añadir una reducida cantidad de compensación, rociada sobre la primera materia con tuberías secundarias.

Los amperímetros necesarios para la medición han de estar provistos de una escala amplia y colocados en el lugar de permanencia del personal de servicio de las máquinas.

La influencia de la humedad de la masa en el consumo de fuerza de la prensa se explica con el siguiente ejemplo:

A título de ensayo, en una fábrica se comprimió la masa en dos formas, una extremadamente dura y otra blanda; se midió el consumo de corriente y se determinó el grado de humedad de la masa, resultando que la diferencia en el contenido de agua entre el prensado duro y el blando fue de $1,5 \%$ referido al peso en húmedo.

El consumo de corriente del motor de accionamiento se diferenció en 30 amperios.

Es decir, las perturbaciones motivadas por el diferente contenido de agua de amasado pueden atenuarse, como se ha descrito, con medios sencillos. 


\section{Reconocimiento de defectos de moldeo}

Los defectos en el prensado se distinguen de los defectos por el secado en que en el producto secado y cocido se hacen visibles grietas, que se producen siempre en las mismas zonas de los ladrillos y son de configuración análoga.

Los defectos de moldeo pueden ocasionar también elevaciones y cavidades en las superficies de corte.

Esto se debe a un avance irregularmente rápido de la masa en la salida de la boquilla.

Sin embargo, se reconocen defectos en que la superficie de los ladrillos crudos se agrietan irregularmente. En la figura 1 se presentan estas grietas de configuración irregular, que deben atribuirse a un secado demasiado rápido $\mathrm{y}$, por lo tanto, considerarlas como defectos de secado.

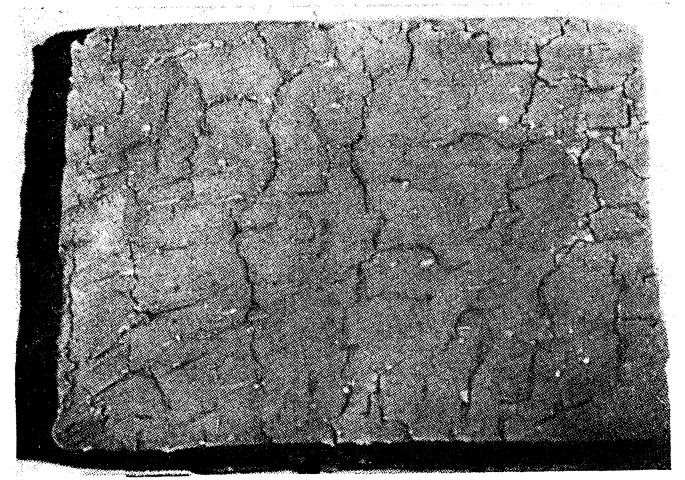

Fig. 1

Para hacer visibles los defectos de moldeo, se han elaborado diferentes métodos en el curso de los años. Estos métodos hay que aplicarlos convenientemente, tanto en el producto (prensado en fresco) recién prensado como en los ladrillos crudos secos o en los ladrillos cocidos.

Las diversas medidas son:

a) Observación de las roturas de secado y de cocción: Si existen defectos de moldeo, los fragmentos del producto seco y cocido del mismo formato son de igual tamaño. Asimismo las superficies de rotura son de configuración análoga.

b) Si los ladrillos secos y cocidos no acusan ninguna rotura, se conseguirá romperlos golpeando ligeramente entre sí dos ladrillos de igual formato: En este caso, hay que observar varios ladrillos y comparar los fragmentos resultantes. Caso de existir defectos de moldeo, los fragmentos serán de igual tamaño y la rotura análoga.

c) Ladrillos crudos se han rociado con agua caliente, sometidos a un chorro de vapor o mantenidos en agua hirviendo: En este análisis tosco se erosionan las partes débiles. Al comparar las roturas de secado o de cocción con la erosión, se observa que las erosiones en el ladrillo crudo se producen allí donde existe la línea de rotura en el producto seco y cocido.

d) Ladrillos crudos recién prensados se extraen de la prensa, aplastan y rompen: También en este caso se producen los fragmentos en la forma que rompen los ladrillos secos y cocidos.

e) Por experiencia se sabe que rompen los ladrillos crudos que se han secado rápidamente: Se ha aprovechado esta circunstancia secando intencionadamente, con la máxima rapidez, ladrillos crudos recién prensados. Para ello se utilizaron varios ladrillos y se comparó la formación de la grieta. Siempre sucede que, existiendo defectos de moldeo, las grietas se originan en el mismo sitio. 
f) Los defectos de moldeo también se reconocen en que los ladrillos presentan diferente espesor: Si se coloca una regla sobre la superficie de corte de los ladrillos, al existir defectos de moldeo se aprecia que la regla no hace contacto en todos los puntos.

Con este método, en ladrillos secos y cocidos, puede apreciarse:

- si se produce un avance angular en la boquilla;

- si el ladrillo crudo avanza en el centro, y

- si todos los nervios salen con velocidad uniforme de la boquilla.

Como es sabido, las masas cerámicas de gran espesor de pared se contraen menos que las de espesor reducido. Ahora bien, los puntos de gran avance a la salida de la boquilla acusan mayores espesores en dicha pared y, como consecuencia de la menor contracción, se reconocen como elevaciones en las superficies cortadas.

g) El sistema más sencillo para determinar defectos de moldeo es controlar el avance de la barra a la salida de la boquilla: Con esto y con la prensa llena se corta lisamente la barra a la salida de la boquilla, se deja salir la masa unos $10 \mathrm{~cm}$ de la boquilla y se mide la longitud del avance en la sección transversal de la barra.

\section{Avance de la barra en la boquilla}

A continuación se muestran unas fotografías sobre los avances comprobados experimentalmente.

En la figura 2 se observa el avance de un ladrillo hueco de 1,5.

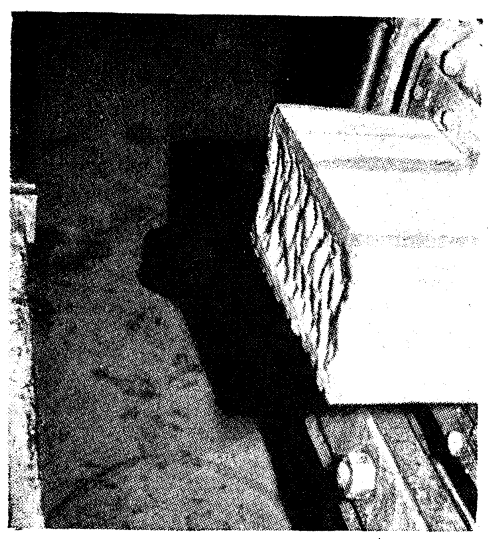

Fig. 2

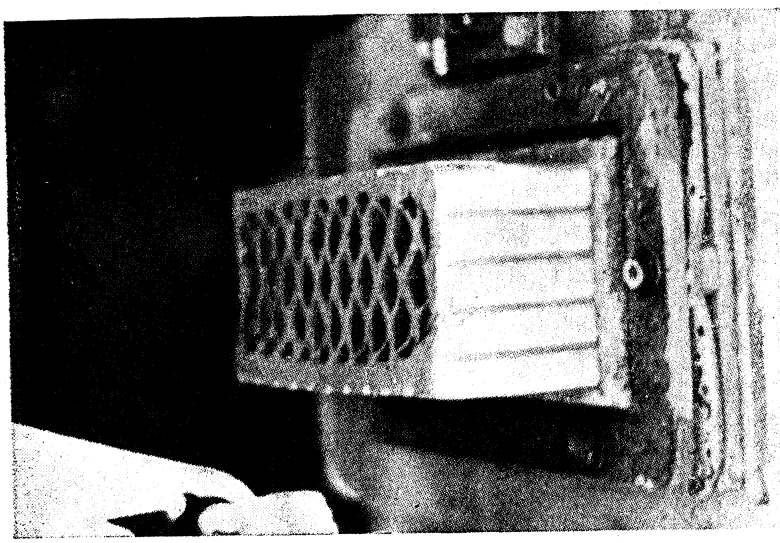

Fig. 3

El lado de la unión está ondulado así como también el avance en los nervios; por lo tanto, está agrietada la estructura de éstos. La cara exterior inferior de la barra avanza con más fuerza (fig. 3). En la zona de los primeros rombos del perforado quedan los nervios muy elevados. Las grietas se producen en esta zona una vez seco y cocido el producto.

La figura 4 muestra para la zona anterior un avance mayor que en la parte posterior de la barra. 
Al aplicar la prueba de aplastamiento y produciendo a continuación la rotura, el ladrillo crudo recién prensado se agrieta en la última capa del avance (fig. 5).

En la figura 6 se ve el avance de un ladrillo perforado de 2,25.

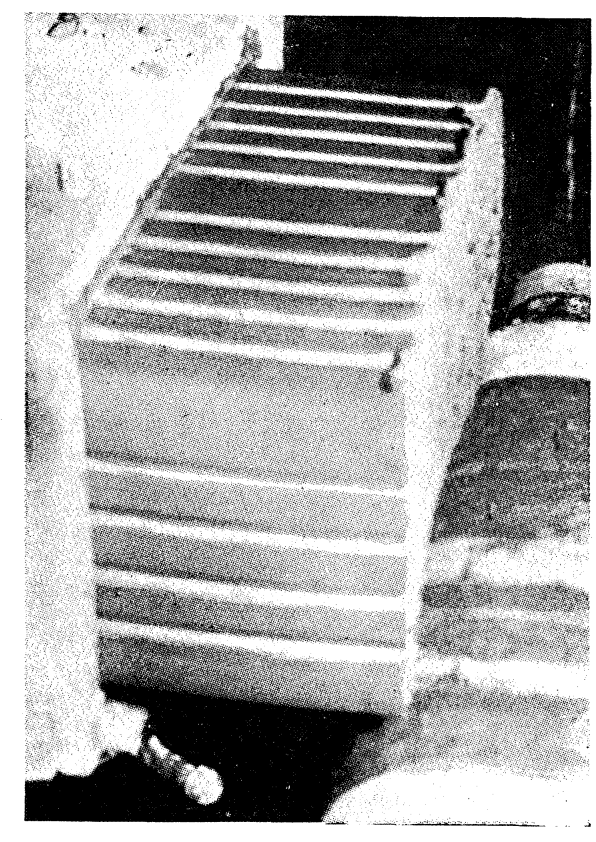

Fig. 4

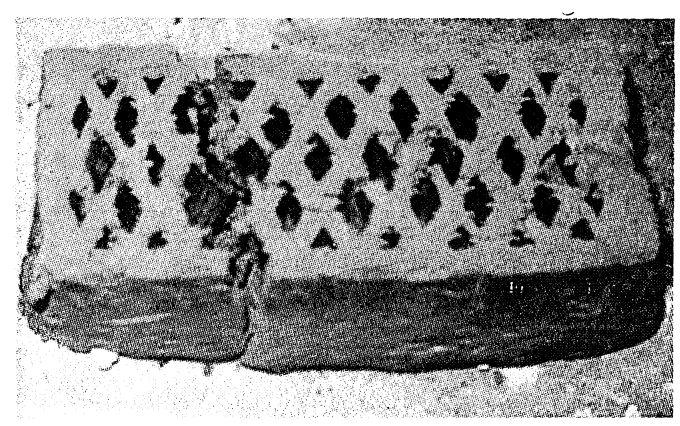

Fig. 5

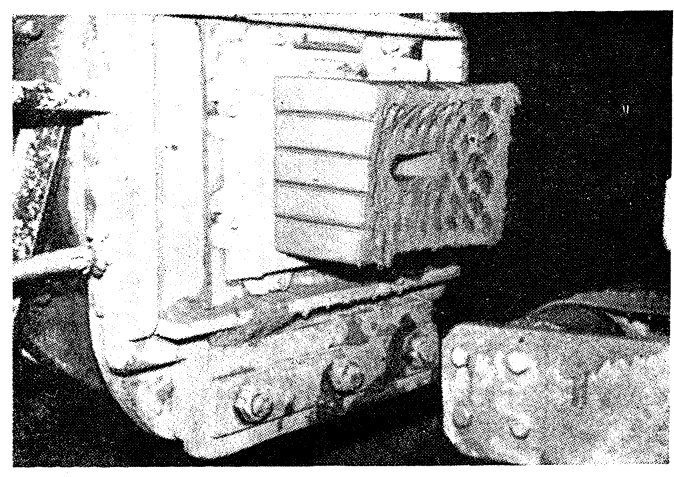

Fig. 6

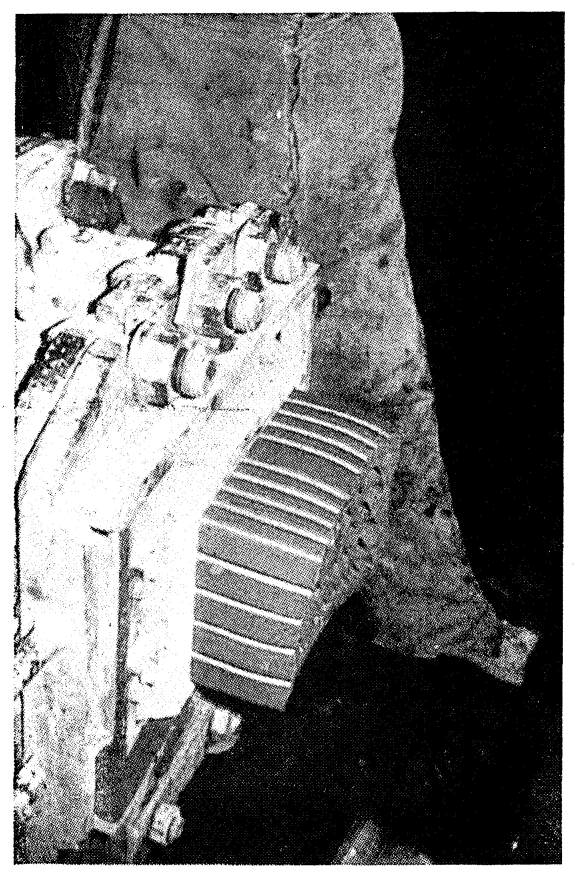

Fig. 7

Al producirse grietas en los tabiques de perforación, el avance se afecta, frecuentemente, como se representa en la figura 7.

En la figura 8 puede apreciarse un avance circular.

La prueba de aplastamiento efectuada a continuación produjo las grietas representadas en la figura 9 , y se hallan en la zona de los tabiques. 

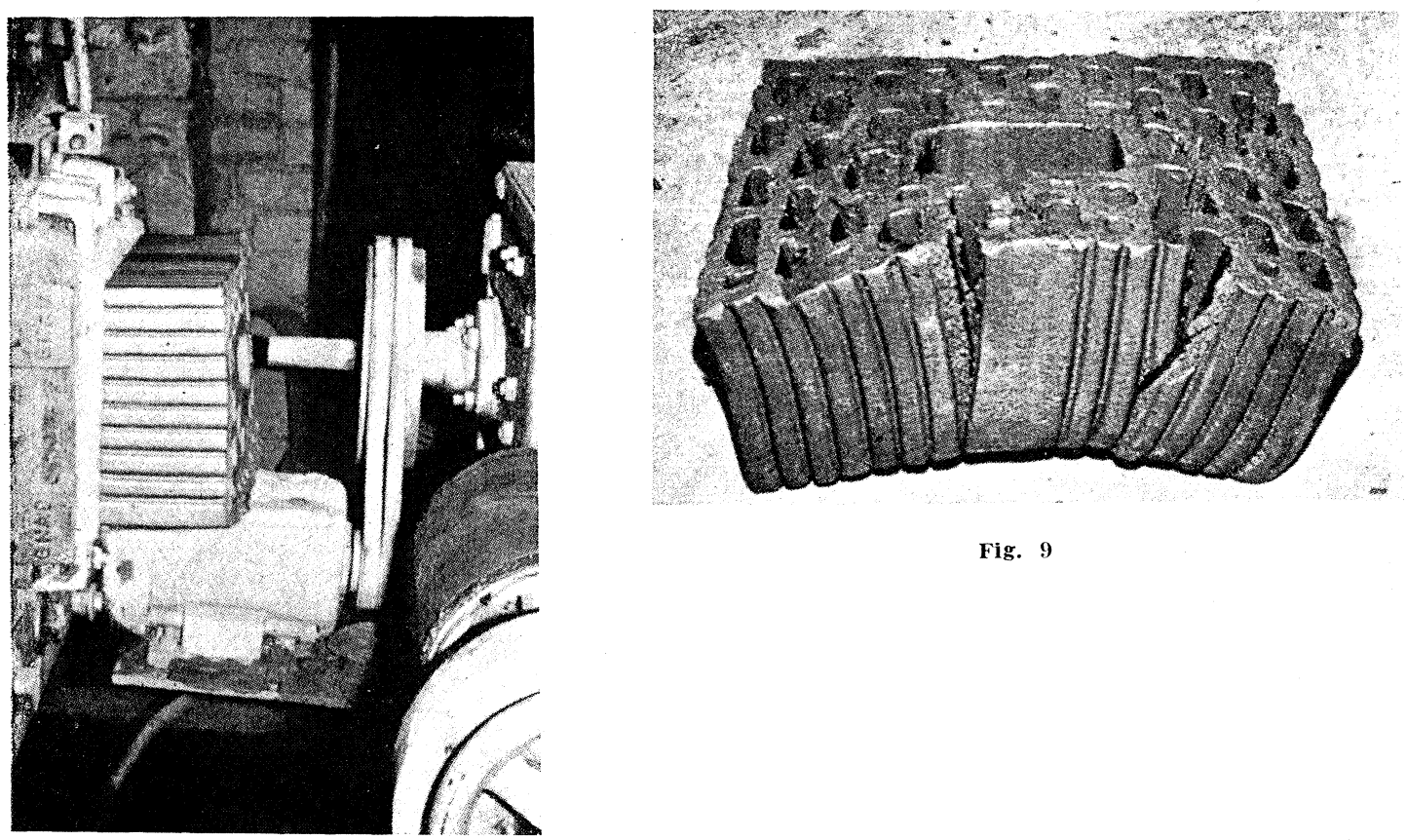

Fig. 9

Fig. 8

Cuando, como en la figura 10 hay un avance semicircular, la cara exterior manifiesta capas adicionales y abajo los nervios se han separado ya de la cara exterior, puede explicarse entonces que un ladrillo crudo así fabricado sólo pueda secarse y cocerse con gran lentitud y que, a pesar de ello, todavía se produzcan roturas de secado y cocción.

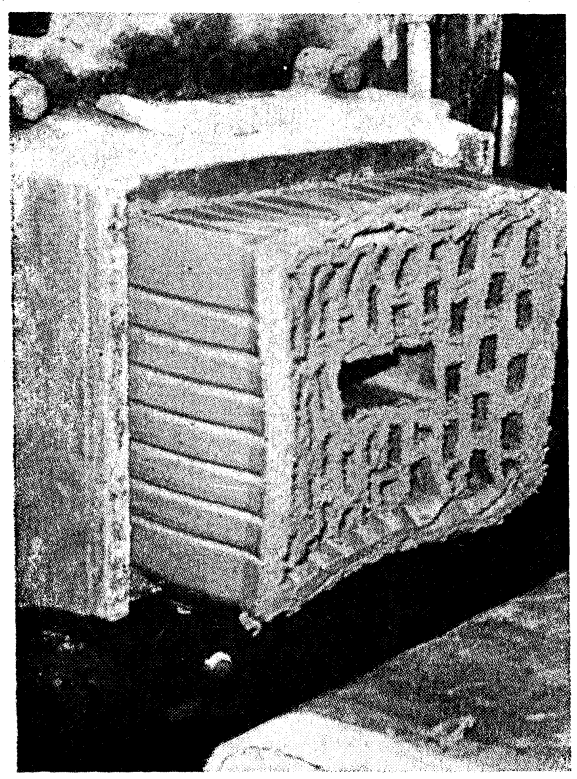

Fig. 10

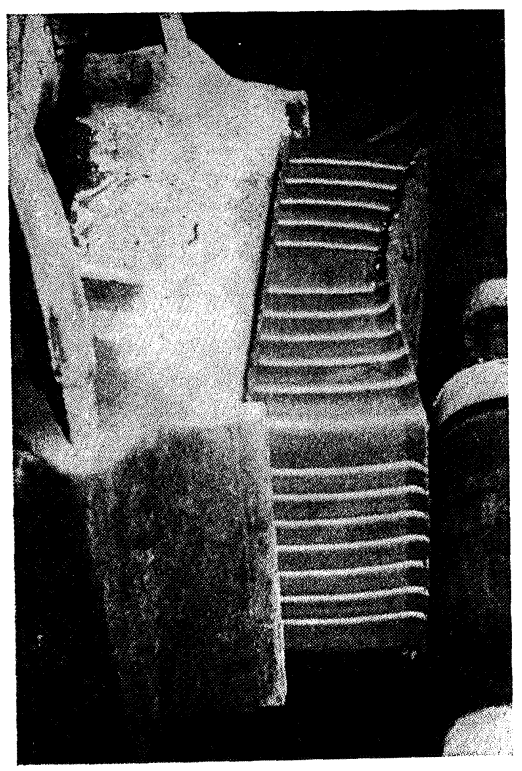

Fig. 11

En la figura 11 se observa el mismo avance desde otra perspectiva. 
En este ladrillo crudo (fig. 12) siempre se observaron grietas en los nervios en la zona de los agujeros de mano después del secado. Como puede apreciarse, el centro queda un poquito más retrasado.

Los avances irregulares representados a la salida de la boquilla pueden atenuarse, en parte, mediante:

- ajuste de los frenos, sienpre que estos existan en la boquilla;

- modificación de la longitud y espesor de los núcleos.

Sobre las medidas usuales para regular los avances de las barras se hicieron indicaciones en otras conferencias y publicaciones. No obstante, el autor llama la atención de que en el curso de esta exposición volverá a hablar de este punto.

Como es sabido, el ajuste del avance de la barra en boquillas bien estructuradas es más fácil de conseguir que en aquellas en las que no se han tenido en cuenta las propiedades de fluidez de la masa en la boquilla.

Con esto se llega al nuevo punto:

\section{Estructura de la boquilla}

En diversas ocasiones se mantiene el punto de vista de que una boquilla se compone de tres piezas independientes entre sí. Esto no es verdad.

Una boquilla se compone de:

- placa frontal;

— caja de la boquilla, y

- soporte de machos para productos perforados.

Estas tres piezas juntas constituyen una unidad. Por este motivo, no se aconseja:

- que en las fábricas no haya más que una a dos placas de boquilla, y

- que en la producción de formatos de tamaño diferente sólo se cambien las cajas de las boquillas.

O sea, que para una buena marcha de la barra es necesario:

- que la abertura en la placa de la boquilla sea tan grande como la entrada de la caja, y

- que la abertura en la placa acuse igual conicidad que la caja de la boquilla.

En todas las máquinas donde hay muy pocas placas, no puede garantizar el fabricante de boquillas ninguna que proporcione un flujo favorable.

Sobre este particular el autor informa que se ha encontrado con boquillas en las cuales la abertura en la placa de la boquilla era mayor que la de la propia boquilla. En la figura 13 puede apreciarse una de estas configuraciones. Además, en la boquilla existían dos tornillos que sobresalían.

Los ladrillos fabricados con esta boquilla acusaban grietas en la zona de los tornillos. Casualmente los tornillos estaban situados en la zona del tabique exterior. En la fábrica se habló de grietas en los tabiques exteriores; sin embargo, eran los tornillos que se hallaban más arriba la causa de la formación de estas grietas. 


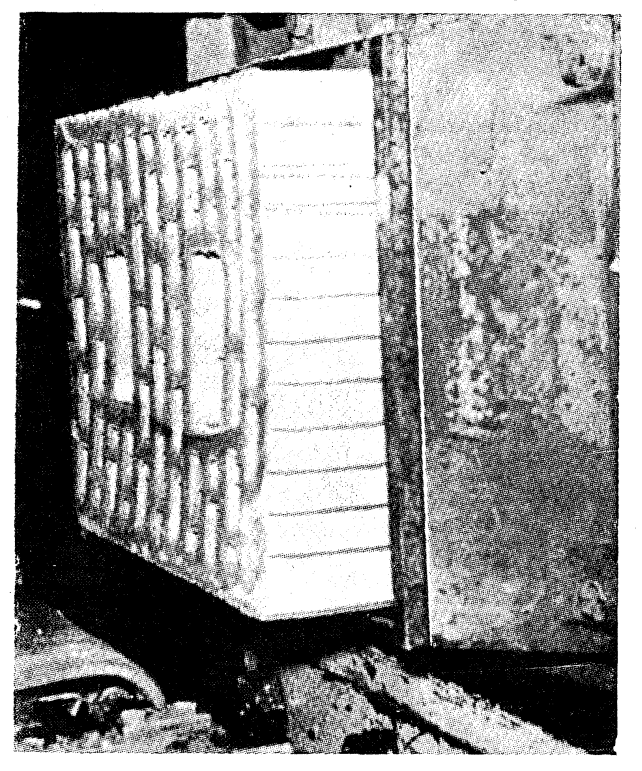

Fig. 12

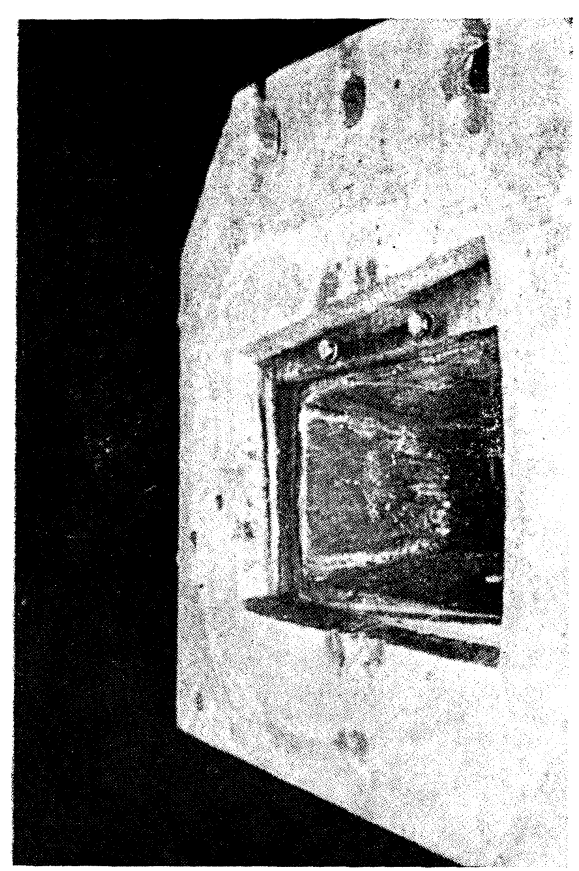

Fig. 13

Se ha rellenado la placa de la boquilla, quitando los tornillos y, a continuación, se ha podido fabricar un producto exento de grietas.

Consecuentemente en las fábricas sería oportuno eliminar todos los tornillos, bordes, etc., que sobresalen. En donde sean necesarios los tornillos, hay que procurar colocarlos con la cabeza embutida.

Tampoco esta boquilla cumple los requisitos (fig. 14). Aquí no se ha solucionado bien el abrir la placa de la boquilla en la entrada angular, porque la caja de la boquilla asoma en la abertura de la placa frenando así la entrada de la masa en los ángulos.

Es mejor realizar la entrada angular en la placa de la boquilla como se muestra en la figura 15.

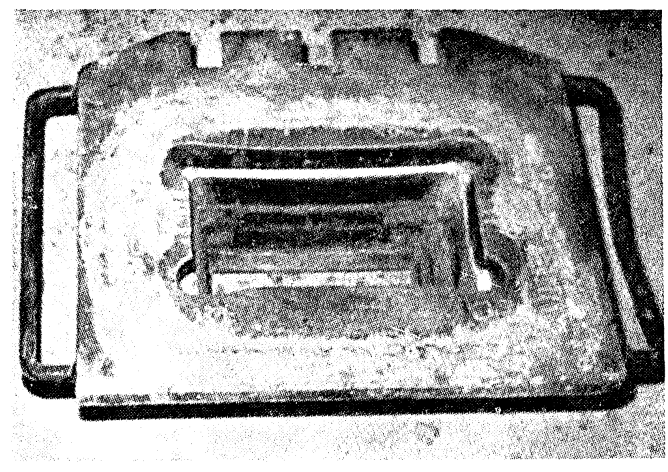

Fig. 14

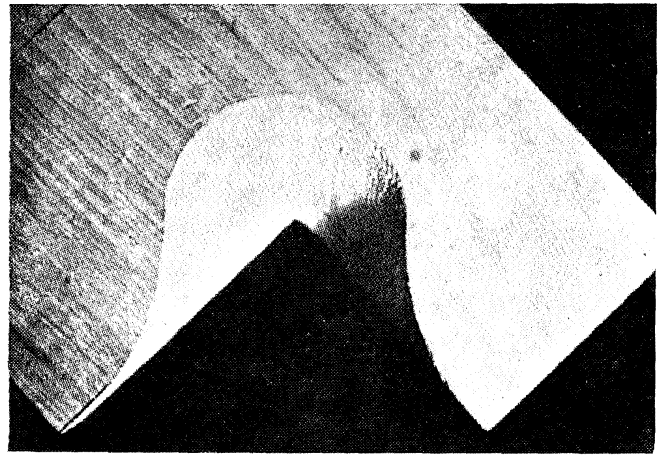

Fig. 15

En la figura 16 puede verse como asoma la caja de la boquilla en la abertura de la placa. En la parte superior de la figura la caja de la boquilla entra más en la placa que en 
la parte inferior. En la parte derecha se muestra la placa escotada de la boquilla para el portamachos (portanúcleo). También aquí se origina un frenado de la masa que entra diferente, de forma que a la salida de la boquilla no puede conseguirse un avance plano.

El portaestribos está fijado a la caja de la boquilla. Por lo tanto, debiera tenerse en cuenta la escotadura en la placa.

Mucho más conveniente es fijar el portaestribo del macho (del núcleo) sobre la placa de la boquilla. Así es posible configurar la abertura en la placa de la boquilla para que sea del tamaño de la caja y que la entrada en la placa de la boquilla vaya acompasada con el paso de la caja.

En la figura 17 se muestra el efecto del tramo en forma de escalón en la entrada de la boquilla.

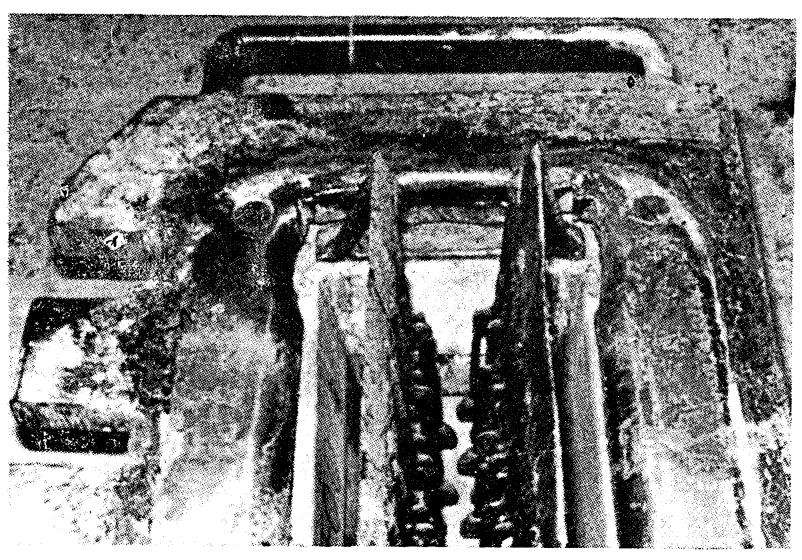

Fig. 16

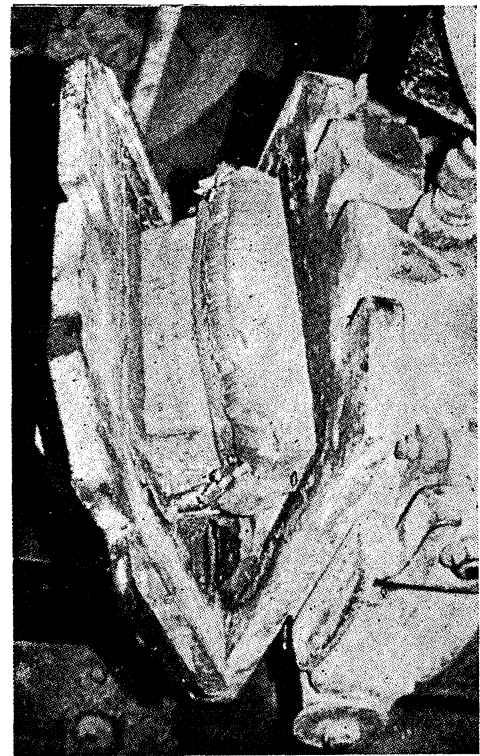

Fig. 17

Ven Vds. que en el tramo entre la caja de la boquilla y la placa no ha fluido la masa uniformemente en todos los puntos y además se ha cortado.

Si las aberturas en las placas se configuran de manera que la placa de la boquilla se recorta como la entrada en la caja, ya no se obstaculiza la masa que entra.

Pero esto es sólo posible si para cada caja de boquilla existe también una placa.

\section{Configuración de los frenos}

Al comprobar la estructura de las boquillas se debe tener en cuenta también la configuración de los frenos para la regulación de la barra.

En la figura 18 puede observarse la disposición y configuración encontradas para los frenos. 
Al avanzar los frenos en el flujo de la masa, se frena al mismo tiempo la entrada angular, y pueden producirse dientes de dragón. Por esta causa, en muchos casos ya no se accionaron más los frenos tampoco ni se reguló el curso de la barra. Los frenos estaban configurados en parte como frenos angulares.

La disposición se encuentra a menudo como se muestra en la figura 19. Al colocar el freno lateral, a pesar de que el freno está achaflanado, se reduce la entrada de la masa en el ángulo de la boquilla.

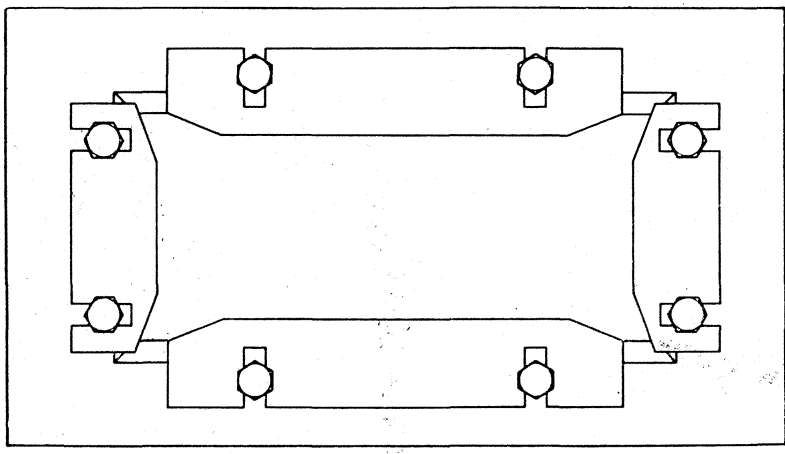

Fig. 18

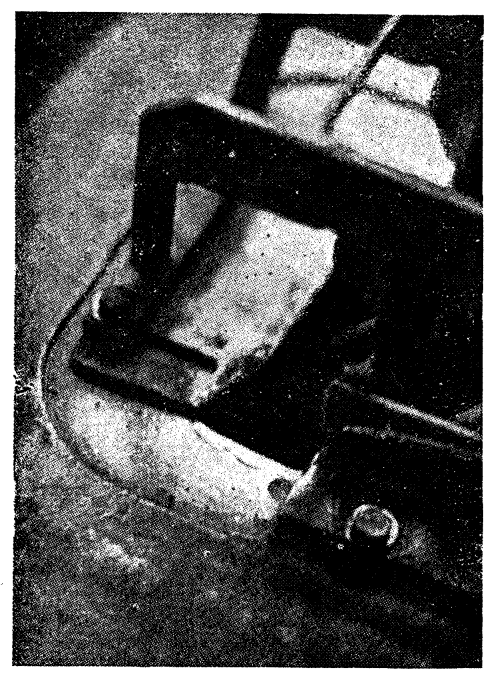

Fig. 19

Los frenos angulares originan, en parte, un agrietamiento o arrancamiento de la masa (fig. 20). Esto no es conveniente, porque la masa que queda detrás del freno puede ir a la boquilla y causar eventualmente una rotura en forma de concha en la capa exterior de los ladrillos.

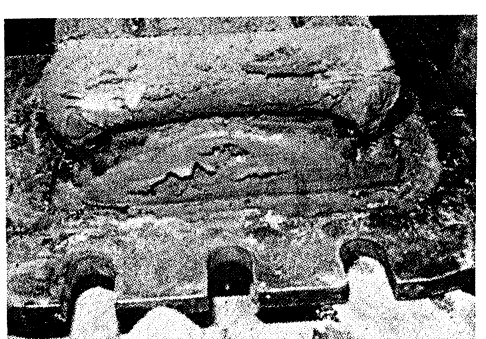

Fig. 20

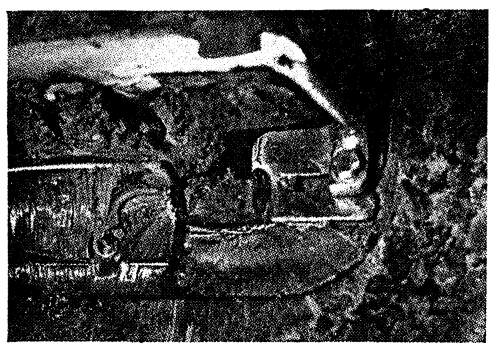

Fig. 21

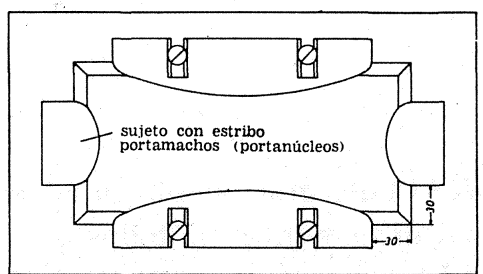

Fig. 22

Es decir, con frenos angulares la masa puede fluir a los ángulos de la boquilla. Así se desgastan en parte los frenos (fig. 21). Como consecuencia se produce en el freno una erosión en forma de gancho. Esto hace que se desgarren los ángulos en la barra. Con el fin de no obstaculizar la entrada de la masa en dichos ángulos y, no obstante, conseguir una regulación del avance, se han provisto las boquillas de frenos redondeados.

El freno desplazable puede introducirse en este caso en el recorrido de la barra, sin que se reduzca el fluir de la masa en las esquinas (fig. 22). Esta medida es sólo apropiada para regular el avance de la capa exterior. 
Como se observará, los frenos se han fijado con tornillos embutidos.

\section{Regulación del avance central}

Si avanza el centro, hay que proceder, en este caso, a un frenado en la parte central de la boquilla.

En el pasado año, el autor todavía se ha encontrado con boquillas en las cuales los frenos estaban dispuestos sobre el portamachos (portanúcleo).

En la figura 23 se han colocado hierros redondos en forma de herradura sobre el soporte.

En este caso se proveyó al nervio central con una pletina de hierro ancha en forma de herradura (fig. 24).

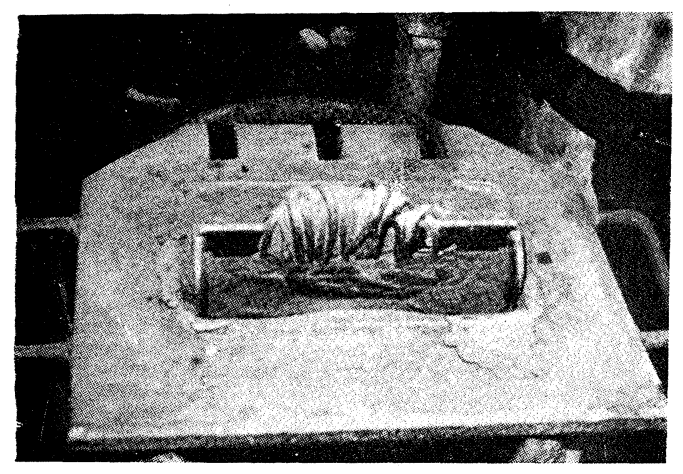

Fig. 23

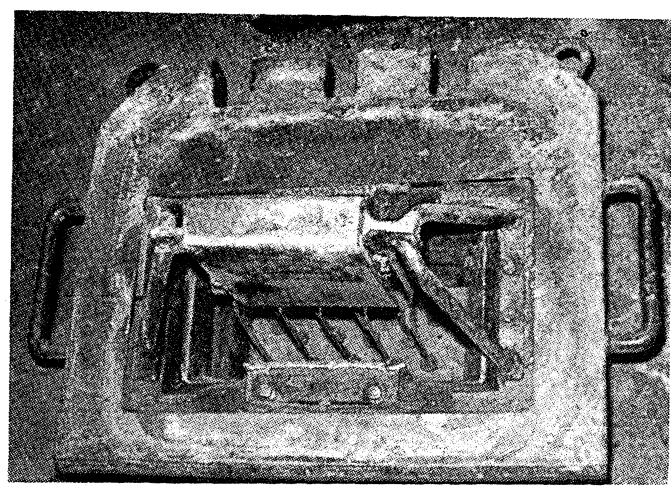

Fig. 24

Es mejor regular el avance central con los machos. Para ello hay que alargar dichos machos o disminuir el paso de los mismos. También es posible regular el avance central adoptando la forma de una mariposa de cierre. Sobre esto se informará más adelante.

Para esto es condición previa que los machos tengan una configuración favorable al flujo.

Estos machos no acusan casi ninguna inclinación, en la dirección mostrada (fig. 25).

En cambio la parte opuesta tiene una inclinación increiblemente grande (fig. 26).

No es necesario explicar que la magnitud del flujo de la masa en los nervios, o sea, entre los machos, es distinta con esta configuración y, en consecuencia, se hallan extraordinariamente amenazados los puntos de intersección de los nervios.

Tampoco es apropiada esta forma de los machos (fig. 27). Obsérvese la forma extraordinariamente divergente entre sí de los mismos.

Con machos de configuración inadecuada para el flujo, debiera de efectuarse en cada caso la sustitución por otros más favorables.

Caso de que el avance de la barra a la salida de la boquilla tenga lugar, con medios corrientes, de tal manera que sale en forma plana de aquélla, con arreglo a los más modernos conocimientos, siempre pueden producirse defectos de moldeo, debido a que la estructuración del cabezal de prensado y la posición y la forma de la mariposa de cierre también entran a formar parte del moldeo. 


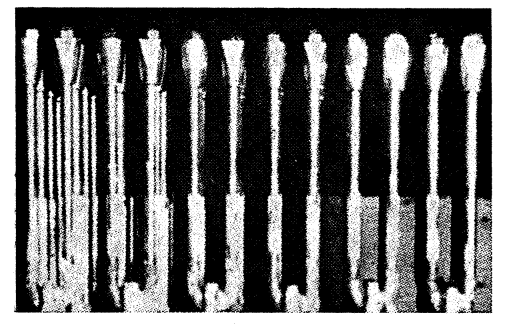

Fig. 25

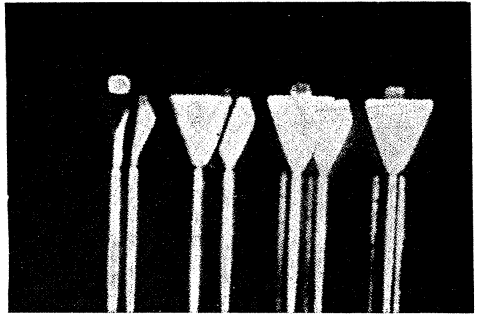

Fig. 26

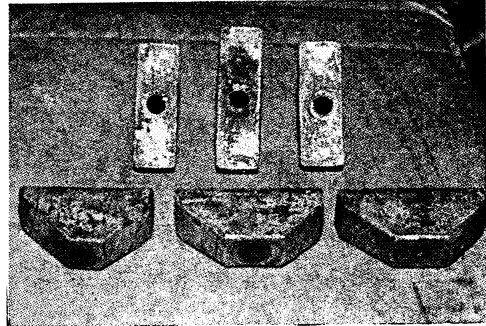

Fig. 27

\section{Alimentación de la masa desde el cabezal de prensado a la boquilla}

En aquellas fábricas que, a pesar de haber regulado el recorrido de la barra en la boquilla, el producto todavía presentaba grietas despúes del secado y. cocido y siempre en el mismo sitio y con configuración análoga, se han tomado recortes a la salida del cabezal de prensado y se han secado rápidamente. Resultó que en dichos recortes se apreciaron grietas de trayectoria análoga a la de las grietas en los ladrillos crudos.

Pudo observarse también que el producto salía retorcido y con velocidad irregular del cabezal de prensado.

La figura 28 es un ejemplo de un avance de la barra. Arriba y en el centro, la barra avanza mucho más que al lado; además, la masa queda rezagada en el centro.

Lo mismo ocurre en la figura 29; en la parte alta y hacia atrás, la salida de la masa es mayor que arriba y delante.

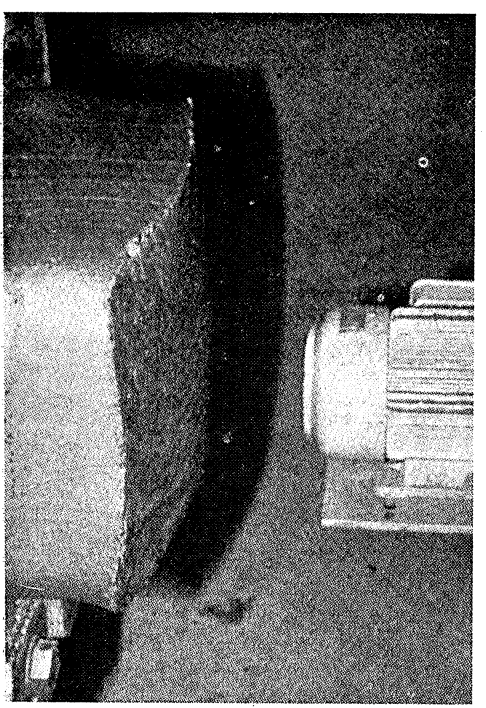

Fig. 28

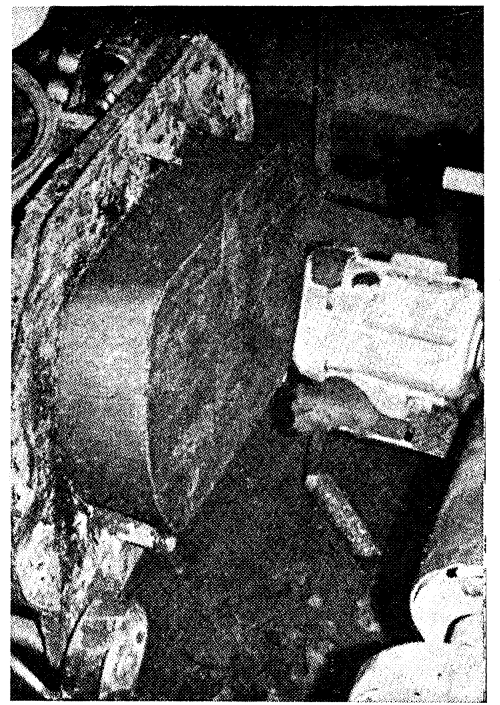

Fig. 29

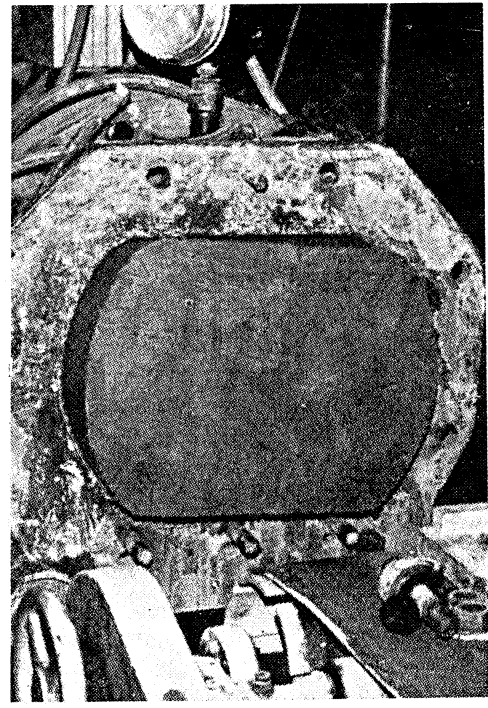

Fig. 30

Abajo y delante el avance es aproximadamente el mismo que arriba y atrás. Por consiguiente, la masa sale, visto diagonalmente, a diferentes velocidades del cabezal de prensado.

El retorcimiento de la masa se presenta en la figura 30. 
También en esta salida se observa un volteo del material (fig. 31).

En algunos casos, a la salida del cabezal de prensado fueron reconocidas zonas en las que la masa no se había cerrado completamente. (fig. 32).

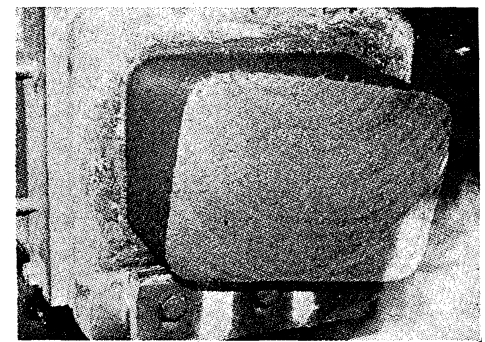

Fig. 31

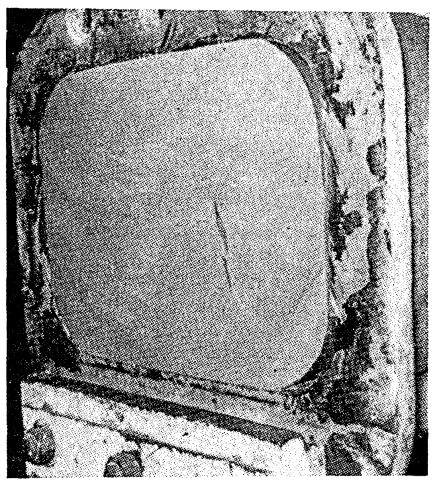

Fig. 32

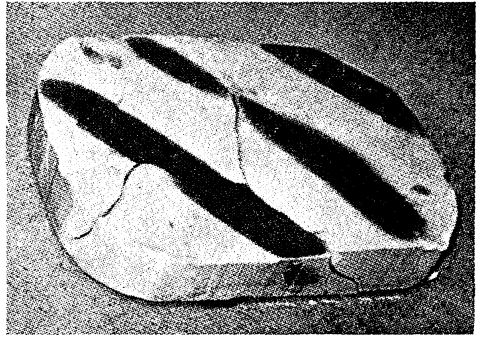

Fig. 33

El recorte que se secó rápidamente y en el que en crudo no podía reconocerse que no se había cerrado la masa, acusó las grietas correspondientes (fig. 33).

Ahora se muestran recortes de la salida del cabezal de prensado secados rápidamente, en los cuales las grietas se manifestaban en forma análoga en el ladrillo seco y cocido (fig. 34). Aquí aparece una estructura circular, en la que las grietas llegan hasta la capa exterior (fig. 35).

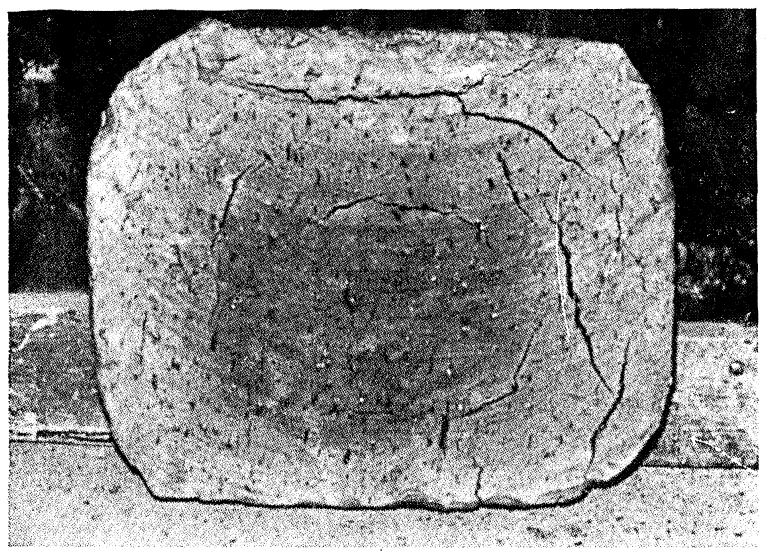

Fig. 34

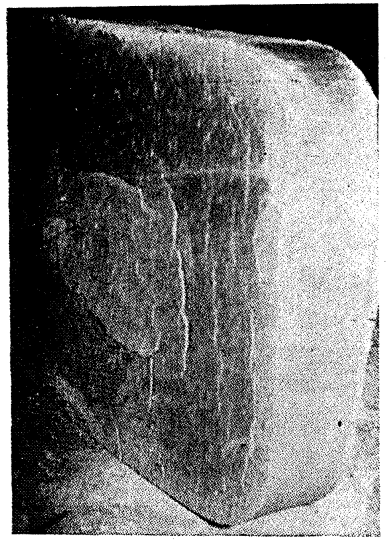

Fig. 35

Las grietas laterales se formaron en el sentido de la barra.

Otro recorte con grietas puede observarse en la figura 36 .

Ha preocupado pues en nuestro trabajo la forma de los cabezales de prensado y elaborado una configuración favorable al flujo del material. El nuevo cabezal de prensado fue solicitado como patente por el Instituto para investigación de ladrillos. 


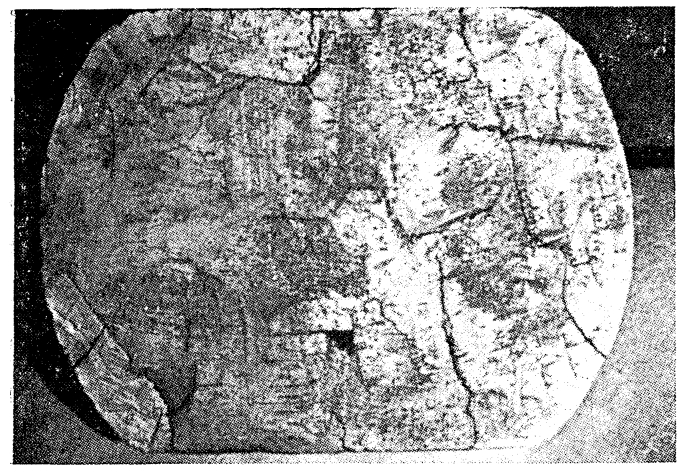

Fig. 36

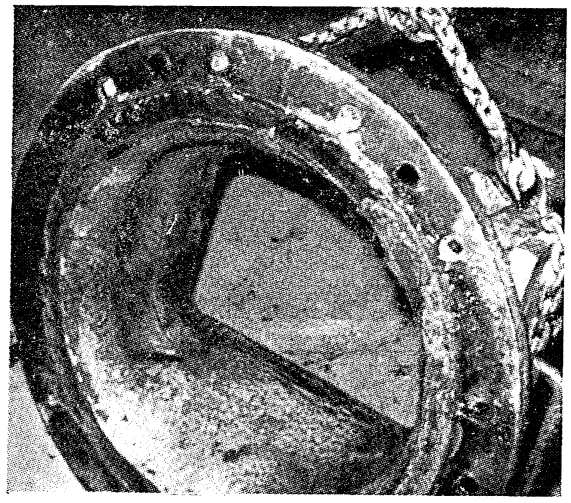

Fig. 37

De los ensayos con diferentes tipos de cabezales de prensado, ha resultado lo siguiente:

Los cabezales de prensado empleados hasta ahora, presentan a menudo compuertas de vaciado (fig. 37). Los tapones de las compuertas de vaciado no llegan siempre hasta la parte interior del cabezal de prensado. En consecuencia, se fija masa en estos recodos. Como es sabido, la resistencia al rozamiento es mayor al fluir masa sobre masa que al fluir masa sobre metal.

Esta es la causa de que el flujo de la masa quede frenado en las compuertas de vaciado y que, por lo tanto, el avance de la barra en la boquilla sea menor en los lados que en el centro.

Los cabezales de prensado normales presentan abajo y arriba una superficie plana, de estructura triangular favorable al flujo. Los lados están configurados, en parte, sin pendiente.

Por la configuración angular, disminuye la alimentación de masa en la entrada angular de la boquilla.

En los ensayos de prensado realizados con las boquillas equilibradas, se observó que la barra acusaba siempre un mayor avance arriba y abajo que en los lados.

Esto era la consecuencia del distinto rozamiento en las compuertas de vaciado y de la configuración de los cabezales de prensado en sus partes superior e inferior.

En la figura 38, la mencionada superficie triangular está más marcadamente configurada que en la figura anterior.

Con este cabezal de prensado, se dan también los defectos en las compuertas de vaciado, con la superficie triangular arriba y abajo (fig. 39).

En la figura 40 se presenta el cabezal de prensado perfeccionado. La pendiente del cabezal de prensado está configurada de forma que desde la sección circular, o sea, de la entrada hasta la salida, siempre hay una pendiente continuada, no existiendo superficies de igual pendiente.

Además, los lados presentan también estrechamientos configurados de acuerdo con la salida del cabezal de prensado (fig. 40 a). 


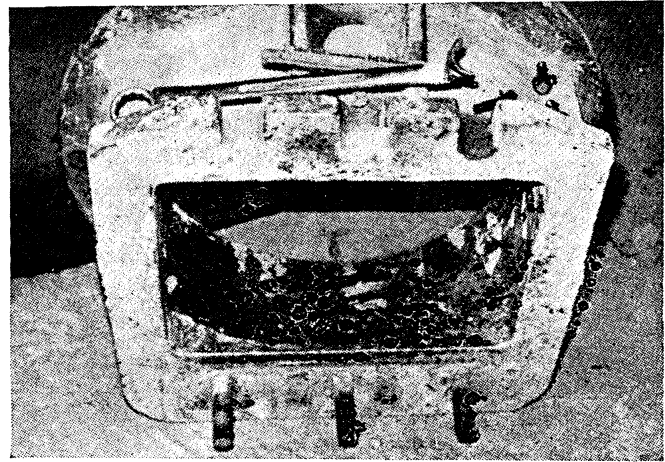

Fig. 38

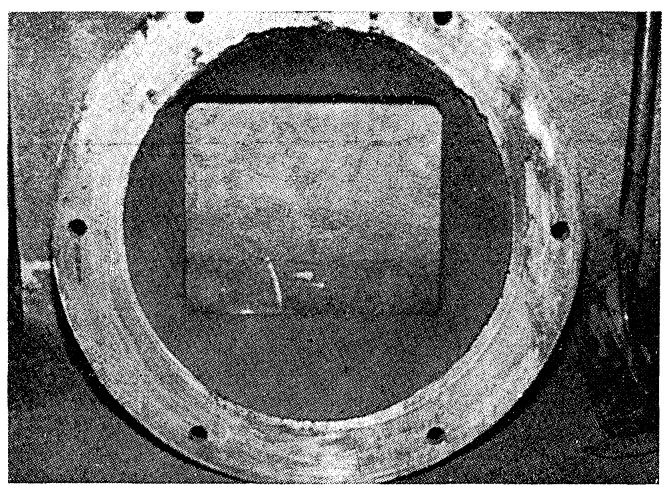

Fig. 40

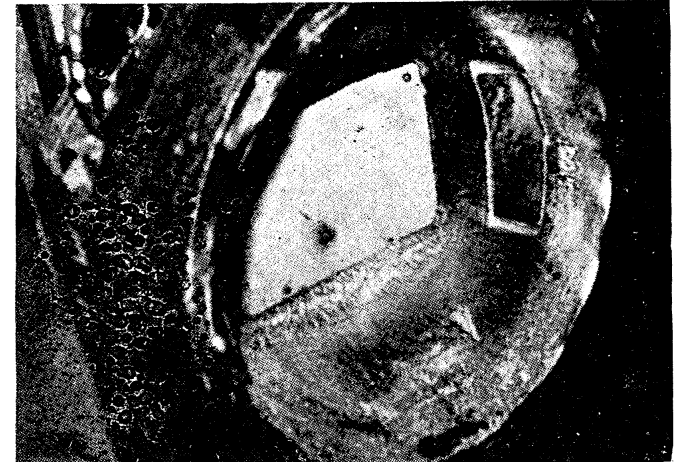

Fig. 39

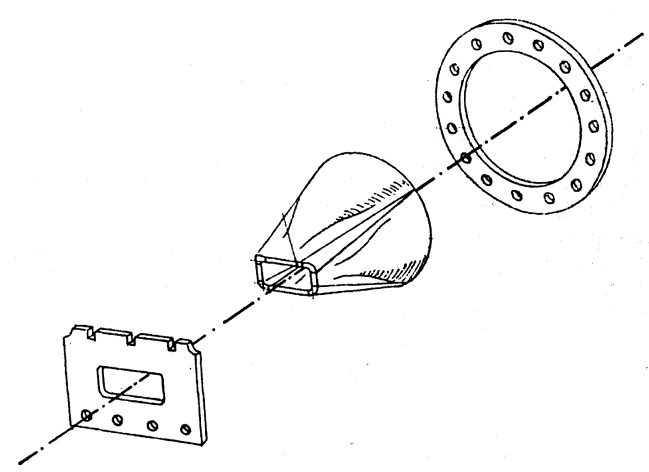

Fig. 40 a

Al paso de la masa por los ángulos del cabezal de prensado ya no queda frenado (fig. 40 a). A esto hay que añadir que ya no existen ángulos en la sección de entrada.

Perfeccionando un redondeado que va reduciéndose hacia la salida del cabezal de prensado, se favorece el flujo de masa en los ángulos. El recorrido más conveniente de la barra se logró cuando la salida del cabezal era del mismo tamaño que la entrada a la boquilla.

Pero como quiera que en la fabricación de material perforado se necesita un portamachos, y para la regulación de la barra se precisan eventualmente frenos en la boquilla, se ampliaron los ensayos en cuanto a la abertura de la salida del cabezal de prensado.

El resultado fue que con una diferencia de $6 \mathrm{~cm}$ entre la salida del cabezal de prensado y la entrada de la boquilla se conseguía un avance plano de la barra a la salida de la boquilla. Si aumentaba la diferencia, ya no se obtenía completamente el mismo favorable recorrido de la barra.

De acuerdo con los ensayos, se ha visto que la relación entre la salida del cabezal de prensado y la entrada de la boquilla debe ser de 1,5 a 2,0. Aquí ya existe un compromiso. La relación favorable debería ser, naturalmente, 1,0. 
De estos resultados surge la exigencia de que al cambiar los formatos de los ladrillos ha de procederse también a un cambio de los cabezales de prensado.

Los formatos

$<240 \times 113 \mathrm{~mm}$,

$240 \times 113$ a $240 \times 175 \mathrm{~mm}$,

$>240 \times 175 \mathrm{~mm}$,

pueden fabricarse cada uno con un cabezal de prensado especial.

Una confrontación de la producción de grietas con cabezal corriente y modificado en un recorte de masa del cabezal secado rápidamente se ve en la figura 36 .

Un recorte del cabezal de prensado modificado secado rápidamente puede observarse en la figura 41 .

La velocidad de secado fue la misma en ambas secciones (recortes).

En otra prensa se observó el aspecto representado en la figura 42.

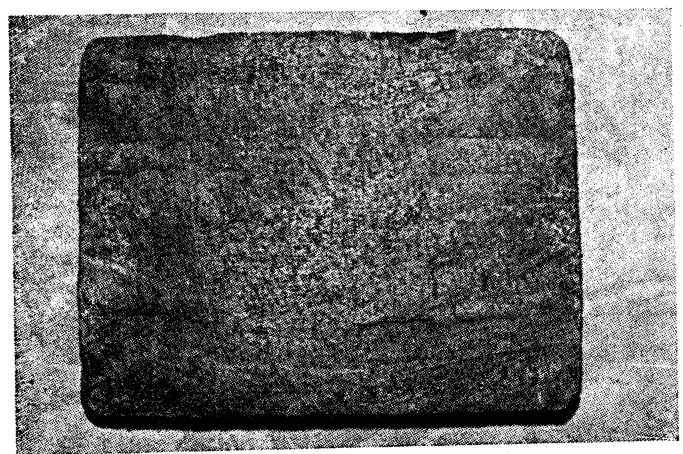

Fig. 41

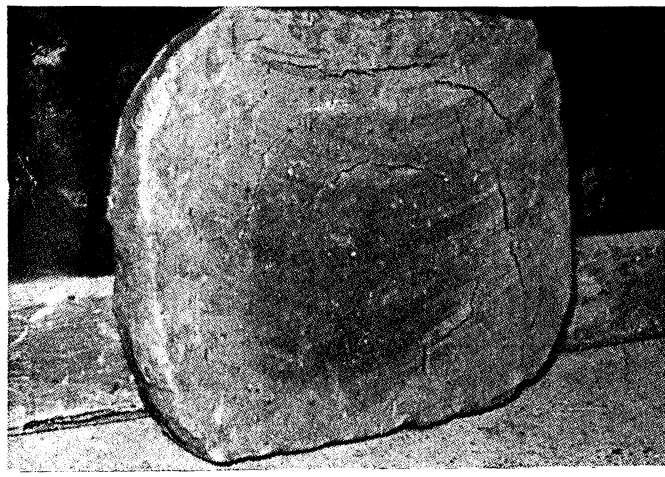

Fig. 42

Modificando el cabezal de prensado y la forma de la mariposa de cierre se corrigió el defecto (fig. 43).

Se reconocen aquí dos grietas en forma de $\mathrm{S}$ superpuestas.

El sinfín de la prensa estaba acondicionado con una mariposa doble dispuesta detrás de la mariposa de cierre. Se ha separado una de las mariposas de la mariposa doble y continuado con los ensayos de prensado. El resultado confirma (fig. 1) que ya sólo existe un defecto de secado. Esto es natural, ya que el recorte se secó intencionadamente a una velocidad extremadamente rápida.

El que la mariposa de cierre influye en el flujo de la masa en el cabezal de prensado, se explica con otro ejemplo.

En la figura 44 se colocó un nuevo cabezal de prensado y se mantuvo la antigua mariposa de cierre. Como se ve, el recorte de la salida del cabezal está muy agrietado.

También en esta prensa se ha modificado la mariposa de cierre, de forma que su superficie tienda hacia adelante (fig. 45). 


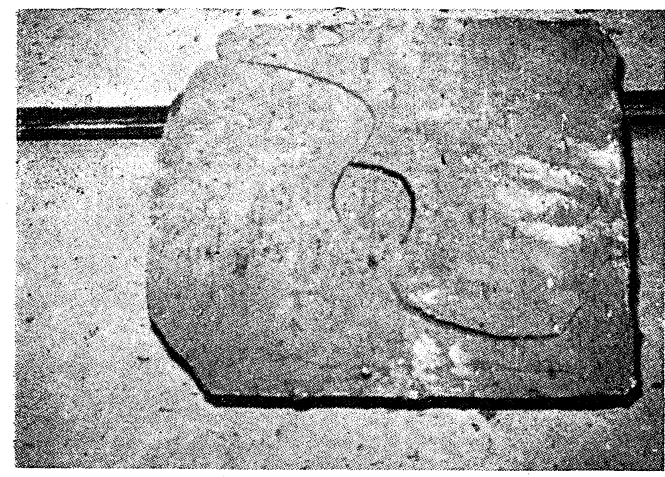

Fig. 43

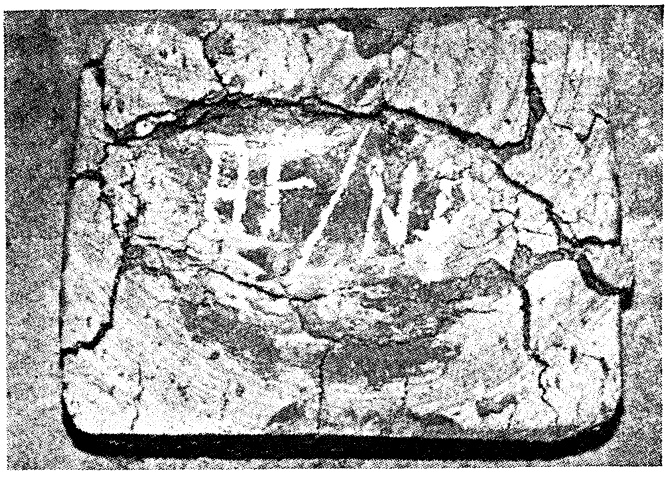

Fig. 44

Puede reconocerse el efecto de la modificación de la mariposa de cierre, al disminuir el número de grietas.

De acuerdo con los resultados obtenidos en los ensayos con los nuevos cabezales de prensado, en los cuales se manifestó además la influencia de la mariposa de cierre, sobre todo en la dirección del flujo de la masa dentro del cabezal, nos hemos ocupado también de dicha mariposa de cierre.

\section{Repercusión de la forma de las aletas de cierre en el avance de la masa a la salida de la boquilla}

Con un avance irregular de la masa en el cabezal de prensado, al controlar más detalladamente el rendimiento de paso de la mariposa de cierre, resultó ser en los distintos casos de $1: 5$ (fig. 46).

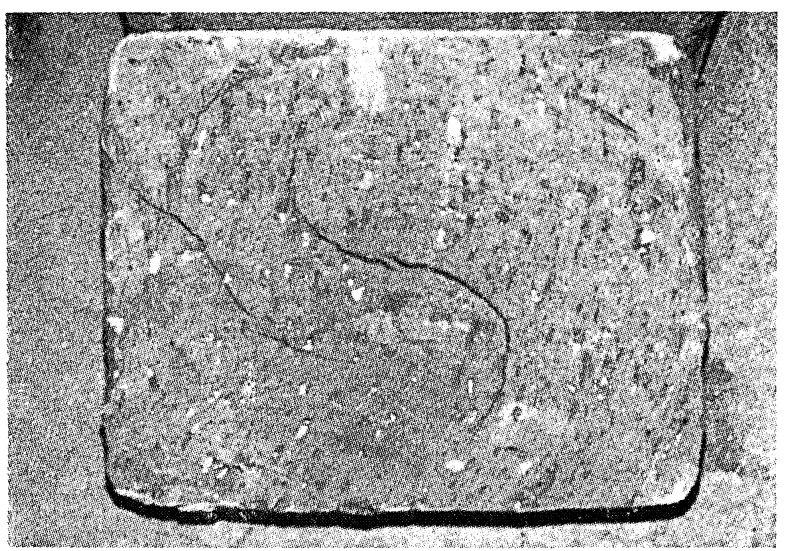

Fig. 45

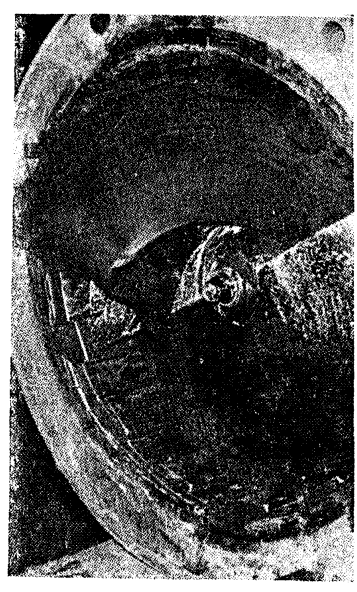

Fig. 46

Este es un ejemplo extraordinariamente craso, pero con el que desgraciadamente nos encontramos demasiado a menudo.

Hay que resaltar que el control de la carga de las mariposas de cierre se efectuó siempre con la prensa llena. 
Al volver a medir los pasos de esta mariposa de cierre, resultó que tuvo que admitir con estas diferencias las masas transportadas por el sinfín de un paso, ya que los pasos entre las mariposas eran de diferente ancho.

En otra prensa había que homogeneizar el flujo disperso de masa comprobado por la fábrica a la salida de la boquilla mediante eliminación de una sección de una mariposa (fig. 47). Pero la fábrica no consiguió mejorar la calidad de los ladrillos crudos.

Esta forma de la mariposa de cierre produjo un avance a tirones de la masa a la salida de la boquilla.

Debido a la falta de sección en una de las mariposas, no hubo ningún avance continuo de la masa en el cabezal de prensado y no se pudo eliminar, por lo tanto, el defecto propiamente dicho, o sea, el diferente flujo de la masa a la salida de la boquilla.

Con arreglo a nuestras experiencias, la mariposa de cierre hay que configurarla de modo que:

1) adopte una superficie cerrada;

2) acuse el diámetro del cilindro de prensado;

3) no șe separe una mariposa como se muestra aquí;

4) sea siempre de igual magnitud el paso entre las mariposas;

5) entre el extremo de la mariposa de cierre y el principio del sinfín de un paso -visto desde el cabezal de prensado- haya, por lo menos, una capa intermedia de masa de $80 \mathrm{~mm}$ de espesor, $\mathrm{y}$

6) la inclinación superficial de ambas mariposas acuse en todos los puntos igual ángulo con respecto al eje del sinfín.

En este caso - como se muestra aquí- la masa fluye en la sección detrás de la mariposa y no hacia adelante, hacia el cabezal de prensado.

La instalación del laboratorio móvil de ensayos se realizó en 1950 con el fin de ayudar a las fábricas de ladrillos en la fabricación de productos perforados.

Hoy en día se nos expresa con frecuencia el deseo de ayuda en la producción de ladrillos macizos.

Vamos a describir, ahora, un ensayo que sirvió para la fabricación de ladrillos macizos:

Se ha dejado en la prensa la mariposa de cierre - como se la utiliza para la fabricación de producto hueco- y a la prensa se le ha colocado un nuevo cabezal de prensado y se han prensado ladrillos macizos.

La prueba de aplastamiento creó una estructura circular, y por cierto tal y como se observa en numerosas ocasiones en la fabricación de ladrillos macizos en otras fábricas (fig. 48).

El control de la salida de la masa en el cabezal de prensado produjo la misma estructura circular (fig. 49).

Al producirse la estructura circular, en varias fábricas se ha modificado la inclinación superficial, pero no el paso de la mariposa de cierre; precisamente para la fabricación de ladrillos macizos se utilizan mariposas de cierre con menor inclinación superficial que para la fabricación de material perforado. Con esta modificación y la aplicación de 


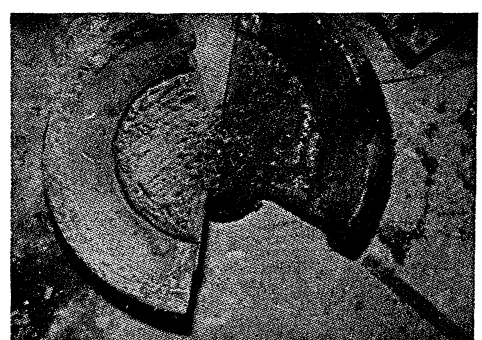

Fig. 47

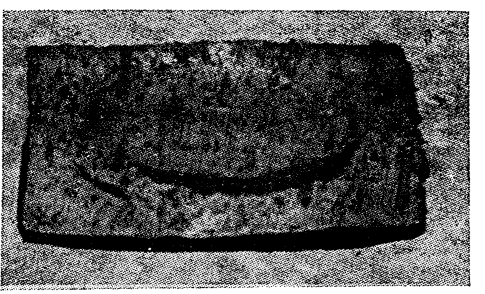

Fig. 48

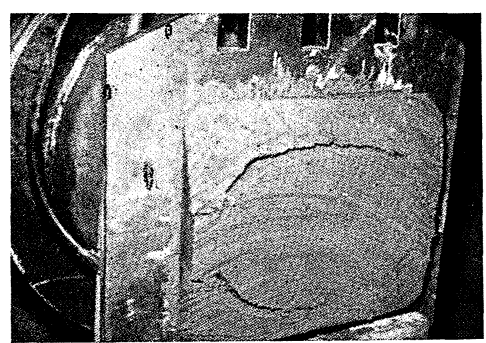

Fig. 49

la nueva forma de cabezal de prensado, pudo conseguirse otra vez una buena calidad de ladrillos macizos. También se han realizado ensayos a la inversa, y para el material perforado y con avance demasiado reducido del centro de la barra se ha inclinado hacia adelante la superficie de las mariposas.

Esta medida aumentó el avance en el centro de la barra para el material perforado y condujo a la homogeneización del avance a la salida de la boquilla.

De los ensayos realizados para configurar las mariposas de cierre, resulta que para la fabricación de ladrillos macizos se necesita una inclinación de las superficies de las mariposas menor que para fabricar ladrillos perforados.

La inclinación de las superficies se rige por el grado de prensado necesario y depende, además, de la disposición de los agujeros del perforado en cada caso, de los machos, de su tamaño y forma y del tipo de configuración del soporte de aquéllos.

Para determinar definitivamente la forma, inclinación superficial y paso de la mariposa de cierre, no se pueden hacer manifestaciones por adelantado. Hay que efectuar en las fábricas, ensayos empíricos de prensado.

A través de numerosos ensayos de prensado se ha reunido la experiencia necesaria y, de acuerdo con las circunstancias de cada caso, se pueden hacer manifestaciones sobre cómo debiera de estar aproximadamente configurada la inclinación superficial de la mariposa de cierre; es decir, que no es necesario hacer un número exagerado de ensayos de prensado.

Debe llamarse la atención sobre el hecho de que para los ensayos de prensado se aplican mariposas de cierre de construcción soldada. Estas pueden modificarse fácilmente con arreglo a los resultados de los ensayos en cada caso.

\section{Resumen}

El autor ha tratado de exponer los conocimientos más recientes obtenidos de ensayos de prensado en el Instituto de Investigaciones Cerámicas de Essen.

Con el fin de obtener una marcha perfecta de la barra, es preciso coordinar entre sí mariposa de cierre, cabezal de prensado y boquilla. Sólo cuando la masa pasa uniforme y homogéneamente del cabezal de prensado a la boquilla, pueden obtenerse las ventajas que proporciona una boquilla construida con arreglo a un flujo correcto.

Por medio de ensayos de prensado adecuadamente realizados, es posible descubrir las causas de los defectos y atenuar mucho o, incluso, eliminar los defectos de moldeo. 